\title{
AGRICULTURA URBANA: uma nova alternativa para a produção de alimentos e melhor qualidade ambiental para a cidade
}

\section{AGRICULTURA URBANA: una nueva alternativa para la producción de alimentos y una mejor calidad ambiental para la ciudad}

\author{
Raphael Pereira de Oliveira Sousa \\ Universidade Federal de Goiás (UFG), Instituto de Estudos Socioambientais (IESA), Goiânia, GO, Brasil \\ rapha.pos@gmail.com \\ Manoel Calaça \\ Universidade Federal de Goiás - Instituto de Estudos Socioambienais (IESA), Goiânia, GO, Brasil \\ manoelcalaca.geo.ufg@gmail.com
}

\section{Resumo}

O presente artigo analisa, a partir da revisão da literatura, as reflexões realizadas por vários autores, sobre a produção de alimentos (Agricultura Urbana e Periurbana - AUP) em espaços urbanos em vários países e no Brasil. Agricultura urbana é a prática de atividades agrícolas dentro do espaço urbano. Inclui todo tipo de cultivo de plantas alimentares, medicinais ou ornamentais, o manejo de áreas de vegetação natural, criação de pequenos animais, beneficiamento e comercialização. Mas o principal papel da agricultura urbana é efetivamente a produção de alimentos para o mercado local, sendo especializada no cultivo de gêneros hortícolas, que de maneira geral são produzidos próximos aos mercados consumidores. A Organização das Nações Unidas para a Agricultura e a Alimentação (FAO) defende que a agricultura urbana é um ponto de partida para desviar a urbanização do rumo atual e criar cidades mais verdes, além de contribuir para garantia da segurança alimentar e nutricional. A partir da pesquisa bibliográfica desenvolvida foi possível constatar que as diferentes experiências de agricultura urbana com resultados positivos, em diversas partes do mundo, tem como fator de convergência a participação dos governos através de políticas públicas de planejamento e gestão territorial, a concessão de acesso a crédito e assistência técnica, além da facilitação de acesso aos mercados. Outro ponto importante é o envolvimento da sociedade civil, por meio de associações, cooperativas, ONGs, e grupos organizados.

Palavras-chave: Agricultura urbana. Agricultura Periurbana. Segurança alimentar. Espaço. Planejamento urbano.

\section{Resumen}

El presente artículo analiza, a partir de la revisión de la literatura, las reflexiones realizadas por varios autores, sobre la producción de alimentos (Agricultura Urbana y Periurbana - AUP) en espacios urbanos en varios países y en Brasil. La agricultura urbana es la práctica de actividades agrícolas dentro del espacio urbano. Incluye todo tipo de cultivo de plantas alimenticias, medicinales o ornamentales, el manejo de áreas de vegetación natural, creación de pequeños animales, beneficiamiento y comercialización. 
Pero la principal acción de la agricultura es efectivamente la producción de alimentos para el comercio local, siendo la especialización en el cultivo de géneros vegetales, que en manera general son producidos cerca de los mercados consumidores. La Organización de las Naciones Unidas para la Agricultura y la Alimentación (FAO) defiende que la agricultura urbana es un punto de inicio para retirar la urbanización del rumbo actual y crear ciudades más verdes, además de garantizar la seguridad alimentaria y nutricional. A partir de la revisión bibliográfica desarrollada fue posible constatar que las diferentes experiencias de agricultura urbana con resultados positivos, en varias partes del mundo, tiene como factor de convergencia la participación de los gobiernos a través de políticas públicas de planificación y gestión territorial, la concesión de acceso a crédito y asistencia técnica, y la facilitación del acceso a los mercados. Otro aspecto importante es la participación de la sociedad civil, por medio de asociaciones, cooperativas, ONGs, y grupos organizados.

Palabras clave: Agricultura urbana. Agricultura Periurbana. Seguridad alimentaria. Espacio. Planificación urbana.

\section{Introdução}

A agricultura urbana e periurbana (AUP) não é uma atividade nova. É prática tão antiga quanto o surgimento das primeiras cidades. Mas é um campo recente de pesquisa. Nas últimas décadas a AUP ganhou mais atenção das organizações da sociedade civil e dos governos em função dos benefícios que a atividade traz para a qualidade de vida da população e para o meio ambiente urbano e com isso surge o interesse da academia sobre o tema. As pesquisas acadêmicas buscam compreender a ocorrência da AUP no contexto das cidades contemporâneas.

O debate sobre a AUP é ainda incipiente e carece de estudos para melhor compreensão dos fatores que a constituem e dos elementos necessários ao seu desenvolvimento. É preciso analisar a agricultura urbana enquanto atividade inserida em um contexto socioespacial caracterizado pela dinâmica da cidade, compreendendo que é um elemento que efetivamente integra o espaço urbano.

O cultivo de plantas (alimentares ou não) e a criação de animais são atividades que, no espaço urbano, apresentam características próprias ao estarem vinculadas e em conflito com o modo de vida, de trabalho, de circulação, de uso e apropriação do espaço que são afetivamente urbanos.

O presente artigo tem como objetivo analisar como a produção de alimentos em espaços urbanos é promovida em países e cidades que se destacam no desenvolvimento da agricultura urbana. 
Para isso, primeiro buscou-se analisar as características que configuram a AUP, embasando a compreensão partir do tratamento do tema no meio acadêmico apoiado em diversos autores como Mougeot (2001), Machado e Machado (2002), Monteiro (2002), Moreira (2008), Moura; Ferreira; Lara (2013). Em seguida, foi elaborada uma revisão bibliográfica sobre o tema, no cenário mundial, visando compreender como a AUP, é desenvolvida em diferentes países e cidade em que se destacam como alternativa de desenvolvimento.

\section{Aspectos conceituais e interpretações sobre a agricultura urbana}

A agricultura acontece em espaços urbanos desde o surgimento das primeiras cidades. Com a evolução das relações capitalistas de produção, a divisão do trabalho gerou espaços especializados. Porém, apesar do processo de urbanização e metropolização, verifica-se a persistência de ruralidades nos espaços urbanos das cidades. A AUP é uma expressão dessa ruralidade e cumpre papel fundamental para manutenção das condições de vida na cidade de um segmento da população urbana.

Nas últimas décadas a AUP tornou-se um lócus de práxis para outro paradigma produtivo e ambiental nas cidades em função dos benefícios que esta atividade traz para a qualidade de vida da população e para o meio ambiente urbano. No meio acadêmico, diversos autores abordam o tema da AUP, como Mougeot (2001), Machado e Machado (2002), Monteiro (2002), Moreira (2008), Moura; Ferreira; Lara (2013).

A definição de AUP refere-se especificamente à localização dos espaços de produção dentro e ao redor das cidades ou áreas urbanas. A área intraurbana refere-se à localização dentro dos limites da cidade, enquanto a área periurbana está próxima às cidades, mas tem uma definição mais complexa pela indefinição de limites, que pode variar dezenas quilômetros dependendo da infraestrutura e custos de transporte (MACHADO; MACHADO, 2002). Para Monteiro (2002) a AUP conceitualmente caracteriza-se por dinâmicas socioeconômicas e práticas agrícolas formadas tanto pela produção hortícola estruturada tanto para abastecimento de mercado quanto para autoconsumo. É realizada em quintais, em áreas públicas ou privadas ocupadas, de formas diversas. A Organização das Nações Unidas para a Agricultura e a Alimentação (FAO), entende que a AUP inclui atividades agropecuárias, pesqueiras e florestais desenvolvidas no interior ou nas proximidades das cidades. 
A agricultura urbana e periurbana se caracteriza pela integração aos sistemas econômico e ecológico urbano, com destaque para as trocas de recursos, produtos e serviços.

La agricultura urbana está ubicada dentro (intraurbana) o en la periferia (periurbana) de un pueblo, una ciudad o una metrópoli, y cultiva o cría, procesa y distribuye una diversidad de productos alimentarios y no alimentarios, (re)utilizando en gran medida recursos humanos y materiales, productos y servicios que se encuentran en y alrededor de dicha zona, y a su vez provee recursos humanos y materiales, productos y servicios en gran parte a esa misma zona urbana. (MOUGEOT, 2001, p. 7).

De fato a AUP extrapola a atividade produtiva. Está integrada ao sistema urbano e ganha dinamicidade. Pode incorporar algum nível de processamento e também a distribuição - e, neste sentido, é fundamental a criação e desenvolvimento de canais de comercialização direta, que elimine a figura dos intermediários e fortaleça circuitos curtos de comercialização.

A AUP é extremamente diversa, incluindo tanto atividades produtivas, como ações de preservação e espaços de lazer. De acordo com Moura; Ferreira; Lara (2013), a agricultura urbana integra desde a produção agroecológica de alimentos, plantas medicinais e ornamentais, até o manejo de áreas de vegetação natural, criação de pequenos animais, beneficiamento e comercialização solidária.

Um papel importante da AUP está relacionado à segurança e soberania alimentar, pois garante a disponibilidade de uma variedade de produtos, em especial gêneros de horticultura, que de maneira geral são produzidos próximos aos mercados consumidores. Mas também pode contemplar a produção de carnes, ovos, leite e derivados, além de uma diversidade de plantas medicinais, ornamentais e temperos. Neste sentido, a FAO (1999) defende que a AUP pode contribuir com a segurança alimentar aumentando a disponibilidade de alimentos para a população mais pobre e garantindo a chegada de alimentos frescos para os consumidores de baixa renda e incrementa a variedade e valor nutritivo dos alimentos disponíveis, além da possibilidade de geração de emprego e renda. Moura; Ferreira; Lara (2013) corroboram com este entendimento e destacam também importantes contribuições para a melhoria do ambiente local, "pela diminuição da quantidade de lixo produzido, manutenção das áreas verdes, aumento da biodiversidade urbana, recuperação de áreas de risco ou embelezamento da cidade" (MOURA; FERREIRA; LARA, 2013, p. 74). 
A partir de uma perspectiva econômica, Monteiro (2002) aponta que a principal contribuição da AUP está na criação de ocupação e renda para a população mais pobre e a consequente melhoria na qualidade de vida. Gera-se oportunidade de emprego em que praticamente não há exigência de experiência e nível de escolaridade, e que, além da segurança alimentar, há possibilidade de obtenção de renda através da comercialização de parte da produção - que pode ainda ser complementada com algum tipo de préprocessamento.

"O emprego de fatores que são pouco utilizados com fins produtivos, como terrenos baldios, água residual tratada, material reciclado e mão-de-obra desempregada, pode resultar em eficiência real dos produtores, além da produção, que geralmente utiliza técnicas que requerem poucos insumos" (MONTEIRO, 2002, p. 41).

Moreira (2008) também destaca o aspecto econômico e social da AUP, afirmando que o debate sob o tema inclui também reflexões sobre a pobreza, as desigualdades sociais e o desemprego como consequências diretas do modelo de desenvolvimento capitalista. Afirma ainda que é, principalmente pelas mãos de trabalhadores pobres e marginalizados da cidade que a agricultura urbana é realizada. Moreira (2008, p. 242) relaciona a expropriação camponesa, pelo processo de expansão das relações capitalistas no campo, com a origem de parte dos agricultores urbanos, afirmando que "antes de serem pobres urbanos, foram trabalhadores da terra", e neste sentido, a AUP seria suportada por saberes novos, aprendidos na luta diária, mas também por saberes tradicionais, herdados da origem camponesa dos produtores. Nesse caso é necessário cautela quanto a origem do agricultor urbano como apresentada pelo autor. É preciso considerar que grande parte dos agricultores urbanos nunca tiveram qualquer vínculo com campo. São sujeitos urbanos, submetidos às contradições e conflitos próprios do espaço urbano e que encontram na agricultura uma alternativa para melhorar sua condição econômica e nutricional.

Diante da necessidade e da importância da agricultura urbana e periurbana para o abastecimento e criação de ocupação de parte do espaço urbano e a geração renda para parte da população, é necessário considerar a disputa por espaço na cidade perante a crescente especulação imobiliária e consequente valorização dos terrenos nas cidades. Monteiro (2002) considera que o rápido avanço dos usos e valores do espaço nas cidades, com aumento da densidade populacional e do preço de terrenos urbanos, configura uma 
barreira para o estabelecimento da AUP, que só pode ser desenvolvida nos poucos espaços disponíveis.

Para que a AU possa ser considerada como opção de geração de ocupação e renda, é necessário que haja espaço disponível para o cultivo, o que requer um entendimento e postura política adequada frente à importância dessa atividade, criando um ambiente para discussão de políticas que possam ampliar a agricultura urbana. (MONTEIRO, 2002, p. 42).

Esta é uma barreira que precisa ser considerada. Por não ter condições de arcar com o preço da terra, os agricultores urbanos realizam a produção em espaços sem segurança, muitas vezes ocupados ilegalmente ou arrendados em curto prazo. Diante desta realidade, Monteiro (2002) aponta que há alternativas viáveis e experimentadas em cidades pelo mundo, como terrenos residenciais privados, margens das vias de transporte, margens de rios, zonas de propriedade pública, quintais, comunidades de produtores urbanos em terrenos públicos, produção em telhados ou lajes, jardins verticais, cultivo de pomar nas ruas e cultivo dentro de edifícios. Porém nada disso pode se efetivar como alternativa sem o envolvimento do poder público através de políticas e subsídios voltados ao desenvolvimento da agricultura urbana.

Pensando na necessidade de buscar alternativas viáveis para o desenvolvimento da AUP, que possam servir de referência, em seguida é analisado como o tema vem sendo tratado e desenvolvido no cenário mundial, a partir de experiências em alguns países bem como em algumas cidades no Brasil.

\section{Agricultura urbana no cenário mundial}

Até a o início da década de 1990 os esforços voltados para a pesquisa e o desenvolvimento da AUP eram bastante dispersos e com pouco ou nenhum apoio institucional. Em relatório emitido em 1987 pela Comissão Brundtland sobre Desenvolvimento Sustentável da Organização das Nações Unidas (ONU) foi recomendado aos governos que promovessem a agricultura urbana como forma de ajudar na reciclagem de resíduos urbanos. A partir da Conferência das Nações Unidas sobre o Meio Ambiente e o Desenvolvimento, realizada no Rio de Janeiro em 1992, houve a convergência de iniciativas regionais e globais de pesquisas e políticas voltadas para a AUP.

Mougeot (2011) aponta que este processo foi liderado por algumas organizações internacionais de desenvolvimento a partir de uma reunião do Grupo de Apoio à 
Agricultura Urbana (SGUA - Support Group on Urban Agriculture), convocada pelo Centro Internacional de Pesquisa para o Desenvolvimento (IDRC - International Development Research Centre) em sua sede em Ottawa no Canadá, realizada em março de 1996. Sob a liderança deste grupo, várias iniciativas se desdobraram a partir de então. Mougeot (2011) lista algumas destas iniciativas que foram importantes no apoio internacional à pesquisa e política sobre a AUP, entre as quais destaca o apoio constante do IDRC à pesquisa aplicada sobre a AUP; o Grupo de Apoio à Agricultura Urbana, que se reúne periodicamente coordenando trabalhos em várias frentes, como treinamento e capacitação, pesquisa e formulação de políticas públicas; a Fundação RUAF e a FAO.

O IDRC foi criado pelo parlamento do Canadá em 1970 com o objetivo de financiar pesquisas nos países em desenvolvimento para produzir conhecimento, apoiar inovações e promover melhores meios de subsistência. A instituição possui sede em Ottawa no Canadá e outros quatro escritórios em Montevideo (Uruguai), Cairo (Egito), Nairóbi (Quénia) e Nova Deli (Índia). A segurança alimentar é um dos temas centrais e neste sentido o IDRC apoia e financia a pesquisa em agricultura urbana e o desenvolvimento de sistemas alimentares sustentáveis em vários países (IDRC, s.d.)

A RUAF Foudation é uma entidade internacional com foco em agricultura urbana e sistemas alimentares sustentáveis que reúne diversas instituições com interesse no tema, como ONG, institutos de pesquisa, organismos internacionais e também parcerias com o setor privado. Fundada em 1999 tem como objetivo contribuir para a redução da pobreza urbana, aumento da segurança alimentar, melhorar a gestão ambiental urbana e estimular a governança participativa nas cidades. Concentra suas atividades em cinco áreas de trabalho: planejamento de sistemas alimentares urbanos sustentáveis; cadeias alimentares curtas e economia local; segurança alimentar e inclusão social dos pobres urbanos; reutilização produtiva de resíduos e efluentes; e agricultura urbana e adaptação urbana às mudanças climáticas. Desde 2001 a RUAF publica uma revista especializada em agricultura urbana como forma de promover o fluxo de informação e o debate sobre a AUP, além de outras publicações como livros, boletins e relatórios de pesquisa, todos focados na pesquisa sobre AUP (RUAF FOUNDATION, s.d.).

A Organização das Nações Unidas para a Alimentação e a Agricultura (FAO) é uma organização intergovernamental, com sede em Roma na Itália, que trabalha com três objetivos principais: 1) combater a fome, a insegurança alimentar e a desnutrição; 2) 
erradicar a pobreza e promover o desenvolvimento econômico e social; 3) promover a gestão sustentável dos recursos naturais em benefício das gerações presentes e futuras. A FAO também se preocupa com o tema da AUP. Além de fomentar a pesquisa e o debate acerca de sua importância, atua com programas em diversos países com o objetivo de ajudar no desenvolvimento de políticas públicas direcionadas à AUP, melhorando sistemas de produção e comercialização (FAO, s.d.).

Uma das iniciativas é o Programa de Horticultura Urbana e Periurbana da FAO, lançado em 2001, com atuação em diversos países em desenvolvimento e financiamento da Bélgica, Canadá, Colômbia, Espanha, França, Itália, Noruega e Venezuela (FAO, 2012). A FAO defende que a horticultura urbana é um ponto de partida para desviar a urbanização do rumo atual e criar cidades mais verdes. São vários os benefícios apontados, destacando-se dentre eles: o aumento da disponibilidade de alimentos frescos, nutritivos e acessíveis à população mais pobre; a melhoria do acesso econômico dos pobres urbanos (ao reduzir os gastos com alimentação e possibilitar a obtenção de renda com a venda de produção excedente); o desenvolvimento econômico, proporcionando um meio de subsistência sustentável e menos vulnerável a crises econômicas e ao aumento de preços dos alimentos; e a melhora do meio ambiente urbano ao associar a gestão de resíduos orgânicos que podem ser direcionados para a produção de insumos.

Além da possibilidade de proporcionar alimento e renda extra para a população pobre de zonas urbanas, a AUP é um elemento chave para reduzir o impacto ambiental das cidades, através da reciclagem de resíduos, da proteção da biodiversidade e do estímulo às economias regionais, reduzindo a dependência do mercado mundial de alimentos. Conforme relatório da FAO (2014) é possível verificar que a agricultura urbana está bastante difundida na América Latina e Caribe, com diversos exemplos de cidades em que a prática é desenvolvido com o reconhecimento de políticas públicas. O relatório elege, conforme avaliação da FAO, as 10 cidades mais verdes na América Latina e no Caribe, a partir da análise dos esforços locais para desenvolvimento da AUP. Destacam as cidades de Havana (Cuba), Cidade do México (México), Antígua e Barbuda (pequeno país nas ilhas caribenhas com cerca de 90 mil habitantes), Tegucigalpa (Honduras), Managua (Nicarágua), Quito (Equador), Lima (Peru), El Alto (Bolívia), Belo Horizonte (Brasil) e Rosário (Argentina). 
O ponto comum entre estas localidades é o apoio político e institucional. O tema está sendo incluído nas estratégias de desenvolvimento urbano e no planejamento de uso da terra, além de receber o apoio de entidades de pesquisa e extensão e de obter oportunidade de acesso a crédito e mercado consumidor. Estas são questões fundamentais para viabilizar a prática da agricultura urbana, visto que do ponto de vista econômico os espaços não edificados nas cidades estão, em geral, em função da especulação imobiliária.

A AUP já é praticada em cerca de $40 \%$ das casas em Cuba e em $20 \%$ das casas na Guatemala. Só em Havana, cerca de 90 mil pessoas estão envolvidas em alguma forma de agricultura urbana. Nas principais cidades da Bolívia, 50 mil famílias são produtoras de alimentos. Em Bogotá, 8.500 famílias produzem alimentos em quintais e pequenas hortas para consumo próprio. Em Quito foram contabilizadas em levantamento da FAO 140 hortas comunitárias, 800 hortas familiares e 128 hortas escolares. (FAO, 2014).

Uma questão de gênero importante que é ressaltada em análise da FAO (2014) sobre a agricultura urbana e periurbana na América Latina e Caribe é o papel da mulher como liderança no desenvolvimento da AUP. Em muitos países as famílias de agricultores urbanos são lideradas por mulheres, com destaque para os exemplos de Caribe, Bolívia, Colômbia, Equador, Honduras e Nicarágua.

Outro aspecto comum apontado pela FAO (2014) refere-se às principais barreiras perante o desenvolvimento da AUP nas cidades estudadas. Quatro são os pontos chaves destacados: falta de espaço; conflitos com as formas de uso urbano do espaço nas cidades; qualidade (ou má qualidade) dos solos disponíveis; e a insegurança quanto ao fornecimento de água. Nos casos das iniciativas com interesse comercial e consequentemente com a necessidade de produção em maior escala, as principais dificuldades apontas foram: alto custo dos insumos; falta de sementes de qualidade; falta de crédito para financiamento da produção; e a dificuldade no acesso aos mercados consumidores.

Diante desses desafios, verifica-se que, para o efetivo desenvolvimento da agricultura urbana é necessário o apoio dos governos, mediante políticas públicas como prioridades para o desenvolvimento urbano. Como gestor dos territórios, dos resíduos urbanos e dos recursos hídricos, a gestão pública pode fornecer ou negar os recursos necessários para a AUP. É justamente este o ponto comum entre as experiências que vem dando certo em diversas cidades. 
A experiência cubana de AUP em Havana é sem dúvida um dos exemplos de maior sucesso no mundo. Teve grande desenvolvimento e expansão com a aplicação de ações integradas com o apoio do governo. O programa de AUP criou em Havana uma rede de lojas de suprimentos agrícolas, fazendas municipais para produção de sementes, unidades produtoras de compostagens e clínicas veterinárias. Além disso, foi viabilizado o acesso a seguro agrícola e crédito para financiamento inicial da produção.

Importante situar o contexto que levou Cuba a desenvolver uma política de agricultura urbana. Após a Revolução Cubana em 1959, o país iniciou um programa de desenvolvimento agrícola com uso intensivo de insumos químicos e maquinário, tornando-se grande produtor de alimentos e um dos maiores exportadores mundiais de açúcar refinado (FAO, 2014). Cuba era totalmente dependente de um modelo de agricultura altamente tecnificado e com uso intensivo de insumos químicos importados.

No final dos anos 1980 e início dos anos 1990 este modelo de desenvolvimento entrou em colapso na ilha. A desintegração da União Soviética, importante parceiro comercial de Cuba, associado ao embargo econômico e comercial dos Estados Unidos, afundou o país em uma severa crise de abastecimento, levando ao racionamento de alimentos e aumento da desnutrição. O caso de Cuba é emblemático para se compreender a importância da soberania alimentar e da necessidade de fortalecimento dos canais curtos de produção e comercialização, em que os produtos básicos e de primeira necessidade são produzidos próximos aos locais de consumo. A dependência de importações e o modelo monocultor da agricultura tradicional colocaram as comunidades em situação de extrema vulnerabilidade, e suscetíveis a risco de desabastecimento.

\footnotetext{
En los tiempos del bloque soviético, Cuba dependía en gran medida de la importación de un alto porcentaje de productos alimenticios básicos. También la agroindustria dependía fuertemente de las importaciones: miles de toneladas de fertilizantes, herbicidas y pesticidas, así como de alimentos balanceados para animales y combustible para maquinaria y transporte. Esto terminó con el colapso del bloque soviético en 1990/91. Durante el año siguiente el país perdió más del $80 \%$ de su comercio exterior. El hambre y la desnutrición en gran escala retornaron a la isla y Cuba enfrentó una crisis económica de considerables proporciones. (ROYCROFT-BOSWELL, 2002, p. 22).
}

Conforme aponta Bourque e Cañizares (2001), com a crise, produtos alimentares passaram a ser desviados das cadeias de distribuição estatais para o mercado negro, causando escassez de produtos básicos. Mesmo gêneros alimentícios que chegavam a ser produzidos na ilha em quantidade suficiente, como frutas e alguns vegetais, acabavam 
perecendo nos campos de cultivo ou nos armazéns, devido à impossibilidade de transporte até os centros consumidores nas cidades pela falta de combustíveis. (BOURQUE; CAÑIZARES, 2001).

Desta forma, os centros urbanos sofreram o maior impacto da crise, pois não havia condições de transporte para abastecimento das cidades. Foi necessário que a população buscasse uma solução local, produzindo alimentos na própria comunidade, pela comunidade e para a comunidade. Bourque e Cañizares (2001) comentam sobre o impacto da crise nas áreas urbanas de Cuba, destacando o movimento voluntário da população que iniciou o cultivo de alimentos nos lotes baldios:

Aunque Cuba está altamente urbanizada, la agricultura urbana prácticamente no existía antes de los años 90. Cuando surgió la crisis, las áreas urbanas fueron las más duramente golpeadas porque era difícil transportar productos hacia las ciudades, dada la escasez de combustible. Como resultado de esto, los habitantes de muchas comunidades empezaron a ocupar silenciosamente solares baldíos para cultivar alimentos (BOURQUE; CAÑIZARES, 2001, p. 27).

Assim, diante do desabastecimento e da insegurança alimentar, os habitantes de Havana começaram espontaneamente a cultivar alimentos em quintais e pela ocupação de praças públicas, lotes baldios, margens de estradas, ou qualquer outro espaço não edificado disponível. Inicialmente, não foram obtidos resultados satisfatórios por diversos fatores como a falta de terras, a falta de insumos adequados, e mesmo a falta de experiência de uma população urbana sem familiaridade com a atividade agrícola. Mas partir de então o apoio governamental transformou o movimento espontâneo em prioridade mediante políticas públicas para desenvolvimento da agricultura urbana.

El desarrollo de la Agricultura Urbana en la ciudad de La Habana tuvo desde su inicio, en 1989, un componente importante: la autorización del gobiemo local para que la población utilizara gratuitamente los espacios vacíos urbanos y periurbanos de propiedad estatal. También se creó una comisión de trabajo integrada por representantes de varias instituciones y de los medios de comunicación para que acompañara y apoyara por diversas vías este desarrollo. (CRUZ; MEDINA, 2001, p. 31).

A agricultura urbana em Havana foi pioneira na transição global para um modelo de agricultura orgânica utilizando como insumo restos de culturas, resíduos domésticos e esterco animal na composição de substrato orgânico com alta produtividade. Criaram-se diferentes tipos de organização de sistemas de cultivo, sustentados em duas principais formas de acesso à terra em Havana. Os produtores que possuem parcelas de terra privadas, tanto em área urbana como periurbana, são chamados de Parceleros, estando 
em geral organizados por meio de cooperativas de crédito e serviços. A partir de 1993 (BOURQUE; CAÑOZARES; 2001) o governo passou a conceder terras em usufruto livre e permanente enquanto fosse desenvolvido algum tipo de agricultura, criando uma nova categoria de agricultor chamado Usufructurario. Nos casos em que vários agricultores se juntam em uma cooperativa e solicita acesso à terra de forma coletiva, estabelecendo uma Unidade Básica de Produção Cooperativa (UBPC). Em todos os casos, o apoio governamental está voltado para o desenvolvimento de cultivos de base ecológica.

Importante lembrar que a transição para este modelo de agricultura, sem utilização de insumos químicos, não foi uma decisão espontânea. Tratou-se de uma necessidade, já que tais insumos eram importados da União Soviética e faltaram após o início da crise. Foi necessário o resgate de técnicas tradicionais para correção da fertilidade do solo, controle de plantas e insetos invasores, utilizando para isso os insumos orgânicos disponíveis. O sistema de produção obteve em pouco tempo altos patamares de produtividade, o suficiente para garantir o abastecimento da população.

Gracias a los sistemas de riego localizado, el uso sistemático de materia orgánica y la aplicación de buenas prácticas hortícolas - como el uso de variedades mejor adaptadas, la rotación y combinación de cultivos y el manejo integrado de plagas y enfermidades -, se pueden producir hortalizas todo el año y obtener cosechas de hasta $20 \mathrm{~kg}$ por $\mathrm{m}^{2}$. (FAO, 2014, p. 11).

Para se chegar a tais níveis de produtividade, foi fundamental o envolvimento de institutos de pesquisa no desenvolvimento de técnicas de cultivos mais elaboradas e de formas mais eficientes de utilização dos recursos orgânicos disponíveis.

Los institutos de investigación fueron encargados de desarrollar técnicas más
sofisticadas como las de compostaje con lombrices, inoculantes del suelo y
biofórmulas. Se abrieron más de 200 centros para la producción de
biopesticidas y para el control biológico de la producción, dirigidos por
graduados universitarios, hijos de agricultores locales. Para 1996 en La Habana
las ordenanzas municipales permitían solamente métodos orgánicos para la
producción de alimentos (ROYCROFT-BOSWELL, 2002, p. 22).

Fica evidente a importância dos projetos de incentivo, de formação e de extensão, pelo poder público que culminou com a criação de uma verdadeira cultura de cultivo de alimentos orgânicos entre a população urbana de Havana. Como resultados desta série de ações integradas resultam os expressivos números da agricultura urbana que foram apurados pela FAO e pelos quais a cidade de Havana foi classificada como a cidade mais verde da América Latina e do Caribe. 
A FAO (2014) avaliou que a rede de AUP em Havana inclui cinco empresas agrícolas municipais, que administram 700 fazendas de variados cultivos, 170 fazendas de gado e 27 de silvicultura, dois estabelecimentos municipais de criação de suíno e de outros animais de pequeno porte, 29 unidades básicas de produção cooperativa e 91 cooperativas de crédito e serviços. Estima-se que a área utilizada na produção agrícola em Havana seja de aproximadamente 35.900 hectares (50\% do território) e em 2012 foram produzidas 63 mil toneladas de hortaliças, 20 mil toneladas de frutas, 10 mil toneladas de tubérculos e raízes, 10,5 milhões de litros de leite e 1.700 toneladas de carne (FAO, 2014). Além disso, há milhares de pátios e parcelas com menos de $800 \mathrm{~m}^{2}$ que são cultivados por famílias para produção de diversos vegetais, condimentos, árvores frutíferas e a criação de pequenos animais para consumo próprio.

Outra cidade em que a AUP tem tido destaque nos últimos anos e que recebe atenção em levantamento da FAO (2014) é a Cidade do México, uma das maiores da América Latina. Como alternativa para garantir o bem-estar ambiental, com disponibilidade de água potável e a manutenção da qualidade do ar, criou-se em 1992 uma área protegida contra a urbanização que ocupa (ao menos formalmente) mais de metade do território da Cidade do México, e que ficou conhecida como Suelo de Conservación. A área protegida contempla bosques, pastagens, áreas húmidas e terras agrícolas.

Um aspecto importante sobre o planejamento para a AUP na Cidade do México é que o Governo do Distrito Federal encara a atividade mais com uma perspectiva ambiental do que propriamente para abastecimento local ou redução da pobreza e desnutrição. Como avanços destacados pela FAO (2014) sobre o desenvolvimento da agricultura urbana na Cidade do México estão: a criação em 2007 da Secretaría de Desarrollo Rural y Equidad para las Comunidades (Sederec), que é responsável por coordenar os esforços municipais voltados para a produção ecológica, livre de insumos químicos ou totalmente orgânicos; e criação de alguns instrumentos jurídicos para respaldo à agricultura urbana como o Programa General de Ordenamiento Ecológico del Distrito Federal, que determina o uso e ocupação do solo, além de definir a área do Suelo de Conservación; a criação da Ley Ambiental del Distrito Federal, que promove a agricultura orgânica a partir da proibição do uso de insumos químicos e de fertilizantes 
sintéticos; e o estabelecimento do Consejo Rural, que representa as organizações de produtores.

Outras cidades como Vancouver (Canadá) e Lisboa (Portugal) também promovem a AUP para além da segurança alimentar, como forma de garantir a sustentabilidade ambiental (MULLINIZ; FALLICK; HENDERSON, 2009; HENRIQUES, 2009). Em Vancouver os esforços pra expansão da AUP compreendem a criação de hortas comunitárias e mercados de agricultores, a implantação de telhados verdes, além de importantes iniciativas de políticas públicas como a criação de um Conselho de Política Nutricional, estratégias de gestão e planejamento urbano e a criação de uma Reserva de Terras Agrícolas (RTA) mantida pelo Governo (MULLINIZ; FALLICK; HENDERSON, 2009). A criação da RTA foi uma forma de limitar o crescimento urbano e garantir a manutenção de terras agricultáveis para a AUP, visto que a disputa pelo espaço urbano e a especulação imobiliária representam sérios entraves para o desenvolvimento da AUP. De forma semelhante, em Lisboa o governo desempenha papel fundamental para a promoção da AUP através do Plano Verde de Lisboa, criado em 2007. O plano urbanístico tem como estratégia entrelaçar as áreas verdes com as áreas construídas, incluindo áreas que são ocupadas pela agricultura urbana, criando corredores verdes ao longo da cidade que abrigam hortas urbanas, parques, jardins e espaços de convívio e circulação (HENRIQUES, 2009).

Em São Petersburgo (Rússia) cerca de 2,5 milhões de pessoas participam de alguma atividade agrícola, cultivando uma área total de cerca de 560.000 hectares, sendo que as principais razões para a prática da agricultura urbana são: a autossuficiência para consumo de verduras frescas, a obtenção de renda extra com a venda de excedentes, o acesso a "alimentos saudáveis", o reaproveitamento de resíduos orgânicos, e a ocupação proporcionada pela atividade como passa tempo. Um aspecto importante é que as autoridades públicas municipais consideram a AUP como importante fator social (que ajuda na solução de problemas de pobreza urbana) e aplicam uma política de subsidio voltada para os horticultores urbanos de São Petersburgo. (MOLDAKOV, 2001). Por outro lado, as principais dificuldades enfrentadas pelos produtores da AUP é a falta de segurança e roubos principalmente nas áreas periurbanas e a dificuldade com o transporte irregular e de alto custo, comprometendo a renda e a possibilidade de acesso aos mercados. 
Para além de ações governamentais, articulações da sociedade civil também buscam superar problemas urbanos através de iniciativas que promovem o desenvolvimento da AUP. Manchester é uma das maiores cidades do Reino Unido e enfrenta problemas cada vez mais comuns às grandes metrópoles, como as desigualdades socioeconômicas e a exclusão social que contribui para aumentar problemas de saúde, incluindo a obesidade (LEVIDOW et al, 2011). Em determinadas regiões há dificuldade de acesso a alimentos frescos e saudáveis, o que agrava o problema. Uma alternativa que vem sendo promovida na cidade de Manchester a partir de iniciativas da sociedade civil é o desenvolvimento da produção e distribuição local de alimentos. Tais iniciativas incluem o parcelamento de áreas urbanas para produção de alimentos, a criação de hortas comunitárias, e serviços de entrega à domicílio como forma de conectar produtores e consumidores. (LEVIDOW et al, 2011). De forma geral, as estratégias na cidade se baseiam no princípio de fortalecimento de cadeias curtas de comercialização direta como forma de garantir acesso a alimentos frescos e com menor custo.

São inúmeras as experiências em todo o mundo direcionadas à expansão da AUP. Há um ativismo político e social que ganha força principalmente nos últimos 20 anos defendendo maior sustentabilidade ambiental e social, vinculado também à crescente preocupação com os impactos relacionados ao modelo agrícola de larga escala e ao uso intensivo de agrotóxicos. O altíssimo nível de urbanização ao qual o mundo chegou (e que segue em ascensão) intensifica em mesma escala os problemas associados às grandes aglomerações humanas.

Na perspectiva da soberania e da segurança alimentar, é preciso criar alternativas para garantir o acesso à alimentação de qualidade, com níveis nutricionais adequados e com disponibilidade de alimentos frescos e saudáveis. Na perspectiva ambiental, é necessário buscar formas de melhorar o meio ambiente urbano com a manutenção de áreas verdes e da permeabilidade do solo, além de alternativas mais eficientes de gerir e reaproveitar os resíduos urbanos. Na perspectiva socioeconômica, é preciso enfrentar o problema da pobreza urbana, principalmente nos países em desenvolvimento, criando possibilidades de ocupação e renda. Estes problemas têm pautado, em certa medida, as políticas de gestão e planejamento urbano em diversas cidades, e a AUP surge como possibilidade de enfrentamento e superação destas questões. 
Conforme apresentado, são diversas as realidades e contextos no qual a AUP tem sido desenvolvida ao redor do mundo, mas é possível apontar como fatores de convergência entre as experiências que merecem destaque a participação dos governos através de políticas públicas de planejamento e gestão territorial, crédito, assistência técnica e facilitação de acesso aos mercados e o envolvimento da sociedade civil, por meio de associações, cooperativas, ONGs, e grupos organizados. A seguir, será feita uma análise sobre o tratamento do tema no Brasil e em algumas cidades brasileiras que desenvolvem trabalho de destaque na promoção de políticas de AUP.

\section{Agricultura urbana no Brasil}

No Brasil o debate sobre a AUP tem evoluído com pesquisas e algum apoio institucional. Santandreu e Lovo (2007) publicaram trabalho que foi um dos primeiros esforços de identificação e caracterização de iniciativas de AUP em regiões metropolitanas brasileiras. Com o título de "Panorama da agricultura urbana e periurbana no Brasil e diretrizes para sua promoção”, o trabalho foi desenvolvido em uma parceria entre a Rede de Intercâmbio de Tecnologias Alternativas (REDE) e a FAO, promovida pelo Ministério do Desenvolvimento Social e Combate à Fome (MDS) e com ativa participação da organização IPES (Promoción del Desarrollo Sostenible), que possui sede em Lima no Peru.

Além de um panorama da AUP em 11 (onze) regiões metropolitanas brasileiras, foram traçadas diretrizes com o objetivo de nortear uma política nacional de AUP no Brasil. A pesquisa considerou as regiões metropolitanas de Belo Horizonte, Curitiba, Porto Alegre, Rio de Janeiro, São Paulo, Belém, Fortaleza, Recife, Salvador, Brasília e Goiânia.

A AUP é composta por diferentes segmentos de atividades inter-relacionadas e complementares. Na análise feita por Santandreu e Lovo (2007) as atividades que integram a AUP foram classificadas em cinco categorias: produção (agrícola, pecuária e de insumos); transformação (processamento com incorporação de valor ao produto final); comercialização; autoconsumo, trocas e doações; prestações de serviços (pesquisa, capacitação, assessoramento, crédito e outros). A pesquisa concluiu que a AUP já era praticada em todas as regiões do Brasil, abarcando grande diversidade de contextos e sendo desenvolvida por indivíduos ou organizações formais ou informais, contando com 
iniciativas do Estado (Federal, Estadual ou Municipal), da sociedade civil (ONG's, cooperativas, associações, etc.), da academia (pesquisa e extensão) e do setor privado.

Apesar do potencial de expansão da AUP, um aspecto importante destacado pelos autores da referida pesquisa foi a ausência de legislação ou de políticas de AUP. Diante desta constatação, foram apontadas seis diretrizes para uma política nacional de AUP: 1) Fortalecer a consciência cidadã em torno dos benefícios da AUP para a sociedade civil e o poder público; 2) Desenvolver capacidades técnicas e de gestão dos agricultores urbanos e periurbanos; 3) Fortalecer a cadeia produtiva e promover ações específicas de fomento à produção; 4) Facilitar o financiamento para a AUP; 5) Promover a intersetorialidade e a gestão descentralizada e participativa; 6) Fortalecer a institucionalidade e a normatização para o desenvolvimento da AUP. (SANTANDREU e LOVO, 2007).

Desde então houve alguns avanços no que se refere à criação de marcos legais para o desenvolvimento da AUP no Brasil, porém ainda são ações esparsas e com alcance pontual. De modo geral, ainda faltam ações efetivas que incluam a AUP na pauta de gestão e planejamento do espaço urbano e que criem mecanismos de fomento para a atividade. Além do Distrito Federal, pelo menos seis estados já criaram políticas estaduais de AUP através de lei específica e outros dois estados ainda não possuem uma política específica para a AUP, mas incluem o seguimento em políticas setoriais voltadas para a agricultura de forma geral.

O primeiro estado brasileiro a instituir uma Política Estadual de Apoio à AUP foi Minas Gerais através da lei no 15.973/2006 (MINAS GERAIS, 2006). Os outros entes da federação que também criaram formalmente uma política de apoio à AUP através de lei específica foram Goiás (Lei no 16.476/2009 (GOIÁS, 2009), Distrito Federal (Lei no 4.772/2012), Mato Grosso (Lei ${ }^{\circ}$ 314/2016), Rio de Janeiro (Lei $n^{\circ}$ 3052/2017), Rio Grande do Sul (Lei no 116/2018) e Santa Catarina (Lei no 17.533/2018). No estado do Espirito Santo não existe ainda política específica voltada para a AUP, e os agricultores urbanos são incluídos como beneficiários dentro da Política Estadual de Assistência Técnica e Extensão Rural Para a Agricultura Familiar e Reforma Agrária (PEATER/ES) criada pela lei 9.923/2012. O mesmo ocorre para no estado de São Paulo, onde também não existe ainda uma política de AUP, mas que criou uma Política Estadual de Agroecologia e Produção Orgânica (PEAPO) através da lei nº 16.684/2018 que tem como 
uma de suas diretrizes o apoio ao desenvolvimento da agricultura urbana e periurbana de base agroecológica. (SÃO PAULO, 2018). Para os demais estados não foi identificado qualquer lei em nível estadual voltada para a AUP.

De forma geral as propostas trazem como principais objetivos gerar empregos e renda, incluindo a agregação de valor ao produto final por algum nível de processamento, proteger a saúde a e segurança alimentar, estimular práticas ecológicas que ajudem no controle da poluição e na melhoria do meio ambiente urbano, além de criar, ampliar ou qualificar programas institucionais de aquisição de alimentos para abastecimento de escolas, creches, hospitais, asilos, restaurantes populares, estabelecimentos prisionais ou socioeducativos, entre outros.

Todas as propostas de Políticas Estaduais para a AUP são instituídas em cooperação com a União e os municípios e tem como instrumentos o crédito e o seguro agrícola, a educação e a capacitação profissional, a pesquisa e assistência técnica, e a certificação de origem e de qualidade dos produtos. São propostas importantes e de fato são aspectos fundamentais. Mas, para que tais políticas tornem-se efetivas e com rebatimento sobre o espaço concreto, interferindo positivamente na criação de espaços produtivos e que se convertam em benefícios para a sociedade é necessário a integração com agentes locais, com o apoio dos municípios, da sociedade civil e da iniciativa privada.

Moura, Ferreira; Lara (2013) corroboram com esta compreensão, apontando a AUP como alternativa produtiva para espaços ociosos nas cidades, o que justifica a sua inclusão nas políticas públicas e nos Planos Diretores dos municípios. Trata-se efetivamente de direcionar recursos para promover formas mais eficientes de ocupação do espaço urbano. E é nesta perspectiva que os Planos Diretores dos municípios podem ser complementados de forma efetiva e eficiente com a prática da AUP, que sejam orientadas pelos princípios da agroecologia, e que tragam novas possibilidades para transformar a vida das pessoas e das comunidades locais.

Do ponto de vista das políticas públicas a discussão sobre a AUP ainda é restrita e insuficiente. A prática da AUP não é nova, mas é um campo de pesquisa recente que deve ser compreendida no âmbito de um movimento que se contrapõe ao modelo urbano atual e à lógica hegemônica que rege o fluxo de produção, distribuição e consumo de alimentos. 
Branco e Alcântara (2011) publicaram trabalho analisando a literatura brasileira que trata das pesquisas sobre a AUP considerando o período de 1996 até 2010. Considerando a adoção da AUP como estratégia de combate à pobreza a partir da virada do século, foram analisados os resultados alcançados no país. Pela análise feita, foi atestado que as hortas urbanas estavam presentes em terrenos públicos e privados, mas eram desenvolvidas predominantemente hortas domésticas e sem qualquer subsídio governamental, ainda que já fosse significativa a existência de hortas comunitárias em terrenos públicos, desenvolvidas com subsídio estatal.

O estudo supracitado analisou relatos de iniciativas em 80 (oitenta) municípios e identificou apenas seis com alguma regulamentação. Isso indica o quanto é recente, no Brasil, a preocupação com políticas para a AUP. Em todo o levantamento os autores identificaram legislação específica apenas para o estado de Minas Gerais, que se referia à já mencionada lei 15.973/2006 que regulamentou a política de apoio à AUP no estado.

É necessário fazer uma ressalva com relação a este dado. Apesar de não ter sido identificada ou considerada, no período analisado já havia legislação específica para apoio à AUP também no estado de Goiás - lei 16.476/2009.

Dentre os aspectos importantes destacados por Branco e Alcântara (2011) estava o fato de que havia predominância de experiências de curto prazo (até 3 anos), o que indica a insegurança que cerca a atividade de AUP. As experiências mais longas, com até 20 anos, eram justamente as que foram desenvolvidas por iniciativas governamentais. Outra característica importante é aquela relativa aos sujeitos envolvidos na AUP. Os produtores eram majoritariamente populações em estado de vulnerabilidade social como desempregados, além de aposentados, pessoas com baixo nível educacional, indivíduos com mais de 40 anos e predominantemente mulheres. Isso indica que a AUP é desenvolvida muitas vezes como complemento de renda e autoconsumo para garantia de condições mínimas de subsistência. Os mesmos autores ainda apontaram um baixo nível de organização nos sistemas de comercialização da produção, mas destacam outras dificuldades sociais, políticas, técnicas, ambientais e econômicas. São aspectos que precisam ser considerados por parte das políticas públicas para o setor e que precisariam ser analisados com maior profundidade em outros estudos.

Os estudos sobre a AUP no Brasil abordam o tema a partir de uma variedade de enfoques. A perspectiva da AUP como ferramenta de promoção da saúde, construção de 
cidades mais saudáveis e com benefícios para qualidade de vida dos sujeitos envolvidos é trabalhada por Ribeiro et al (2012), Siviero et al (2012), Ribeiro, Bógus; Watanabe (2015) e Sperandio et al (2016).

Ribeiro et al (2012) e Ribeiro, Bógus; Watanabe (2015) analisam a AUP no município de Embu das Artes/SP como um novo caminho para o empoderamento local, criação de ambientes mais saudáveis e contribuição para a melhoria da saúde e da qualidade de vida da população. Porém, estes benefícios não podem ser alcançados por qualquer modelo de cultivo. É defendido um projeto de agricultura urbana e periurbana de base agroecológica.

Acredita-se que a agricultura urbana só pode ser considerada como promotora da saúde se praticada à luz da agroecologia, pois essa propõe uma interação harmônica com os recursos naturais, minimiza as agressões ao meio ambiente e considera todos os seres presentes na natureza como aliados, utilizando indicadores biológicos para analisar suas práticas na busca por melhor qualidade de vida. Ao minimizar os impactos sobre a saúde humana, a agroecologia oferece a possibilidade de se obter uma vida mais saudável. (RIBEIRO el al, 2012, p. 386).

A produção de base agroecológica é a alternativa mais adequada para o desenvolvimento para a AUP, como já ocorre em outros países. Além dos benefícios com relação ao meio ambiente, maior agrobiodiversidade e a produção de alimentos limpos, a agroecologia aumenta a autonomia do produtor, tornando-o menos dependente de insumos externos e consequentemente contribuindo para a melhoria no nível de renda.

Em quintais urbanos de Rio Branco/AC o manejo e conservação de plantas medicinais forma sistemas agroflorestais com alta diversidade genética, apoiado nos saberes tradicionais da população do município sobre o uso de plantas medicinais, conforme apresenta Siviero et al (2012), sendo uma oportunidade para a formulação de políticas públicas de saúde, segurança alimentar, conservação de recursos genéticos e geração de renda por meio da agricultura urbana. Já no município de Conchal/SP, a implantação de horta comunitária urbana através de política pública municipal propõe um uso racional do solo urbano, resgatando sua função social. Ao analisar a horta urbana comunitária na perspectiva do planejamento urbano saudável, Sperandio et al (2016) aponta que além da segurança alimentar proporcionada ao beneficiar dezenas de famílias em situação de vulnerabilidade social e carência de recursos, houve uma reconfiguração territorial, na qual a horta comunitária é um marco para a comunidade, se tornando um ponto de encontro e de convívio, resgatando a função de espaço vivido. 
A agricultura urbana orgânica tem sido tratada como alternativa aos modelos de cultivo tradicional, com novas dimensões éticas, sociais e ambientais. Barros (2011) e Hespanhol (2015) exploram experiências de transição da agricultura urbana tradicional para o modo de produção orgânico respectivamente na região serrana do Rio de Janeiro e em Natal/RN. Barros (2011) analisa que a horticultura orgânica no Rio de Janeiro teve início ainda na década de 1980, nos municípios de Teresópolis e Nova Friburgo, voltada para o abastecimento do mercado metropolitano. A promoção da horticultura orgânica no Rio de Janeiro esteve vinculada a preocupações ambientais, ao crescente interesse na produção de alimentos mais saudáveis e a intenção de agregar valor à produção de pequenos agricultores (BARROS, 2011). O mesmo autor destaca que apesar do crescimento da produção alimentos orgânicos, o número de produtores ainda é pequeno comparado ao da horticultura tradicional, sendo a principal barreira, a falta de assistência técnica especializada.

Em Natal/RN problemas ambientais relacionados ao modelo de agricultura convencional, principalmente a contaminação de recursos hídricos visto que muitos produtores cultivam dentro da zona de proteção ambiental da Bacia do Rio Doce, levou o Ministério Público do Estado do Rio Grande do Norte a acionar os produtores para que providências fossem tomadas no sentido de reverter tais problemas. A organização de produtores na Associação de Amigos e Produtores de Hortaliças Moradores do Sítio Gramoré e Adjacências (AMIGS) e a parceria com empresas e instituições foi o mecanismo pelo qual se viabilizou a mudança no modelo produtivo para o cultivo orgânico e reduziu a dependência em relação aos intermediários através da criação de canais de comercialização direta em feiras ecológicas mantidas pela associação (HESPANHOL, 2015). A AMIGS assumiu protagonismo na negociação junto ao Ministério Público para estabelecer um Termo de Ajuste de Conduta (TAC) com o objetivo de eliminar a utilização de agrotóxicos, recuperar áreas degradadas, fortalecer o associativismo e melhorar a renda das famílias que vivem da horticultura por meio do estímulo à comercialização direta dos produtos, criando o projeto Amigo VerdeGramorezinho, que congregou 120 horticultores associados à AMISGS (HESPANHOL, 2015). Além da coordenação centrada na associação de produtores, a transição da produção hortícola convencional para a orgânica teve a contribuição de parcerias com o Instituto de Assistência Técnica e Extensão Rural do Rio Grande do Norte (EMATER - 
RN), o Serviço de Apoio à Pequena e Média Empresa (SEBRAE - RN), a Universidade Federal do Rio Grande do Norte (UFRN) e a Petrobrás visando capacitar os produtores através de cursos, oficinas técnicas e reuniões, além de fornecer recursos para financiar o processo de transição (HESPANHOL, 2015).

A partir da análise do ocorrido em Natal/RN, é possível compreender a importância do envolvimento e coordenação local e do apoio institucional e da academia para o desenvolvimento de projetos viáveis de AUP assentados sobre bases ecológicas.

Outro olhar sobre a AUP no Brasil é encontrado em COMASSETO et al (2013), que analisa a agricultura urbana como fenômeno de consumo (ou anticonsumo), entendendo que a mesma integra uma forma de consumo simbólico que se contrapõe à lógica contemporânea de mercado e remete à um resgate da herança cultural. Conforme conclui Comasseto et al (2013), a agricultura urbana estaria relacionada a construção de um identidade e transmissão de uma determinada imagem ao conjunto da sociedade, indicando que "seus praticantes a realizam não por sua característica utilitária (consumo de alimentos), mas principalmente por sua característica simbólica" (COMASSETO et $a l, 2013$, p. 373).

Esta, pode ser uma das dimensões em que a AUP se apresenta, contudo é preciso considerar o importante papel que desempenha ao garantir a segurança alimentar e melhoria das condições gerais de renda para populações pobres no espaço urbano.

\section{Considerações finais}

A agricultura urbana é uma atividade tão antiga quanto as primeiras cidades. Conceitualmente, pode ser definida de forma objetiva como a prática de atividades agrícolas dentro do espaço urbano. É bastante diversa, abarcando todo tipo de cultivo de plantas alimentares, medicinais ou ornamentais, o manejo de áreas de vegetação natural, criação de pequenos animais, beneficiamento e comercialização. Mas efetivamente, podese afirmar que o principal papel da agricultura urbana se refere especificamente à produção de alimentos para abastecimento de mercados locais, sendo especializada no cultivo de gêneros hortícolas, que de maneira geral são produzidos próximos aos mercados consumidores. Ela atende a um segmento de mercado que, com a expansão das grandes cidades, só cresce - a demanda de alimento. 
Paralelamente, a atividade traz outros benefícios importantes. Do ponto de vista ambiental, a agricultura urbana tem o potencial de contribuir para a manutenção de áreas verdes e da permeabilidade do solo, para o aumento da biodiversidade urbana, para recuperação de áreas de risco, entre outros. Na perspectiva do urbanismo, a agricultura urbana tem o potencial de contribuir na recuperação e revitalização de espaços degradados e subutilizados na cidade, ocupando produtivamente lotes baldios, margens de rodovias, praças e áreas públicas, e toda sorte de espaços não edificados, criando espaços de convívio e de produção de alimentos. No que se refere a questão econômica e social, a agricultura urbana tem o potencial de contribuir para a melhoria da segurança alimentar e nutricional, aumentando a disponibilidade de alimentos para a população mais pobre e garantindo a chegada de alimentos frescos para os consumidores de baixa renda, incrementando a variedade e valor nutritivo dos alimentos disponíveis, além da possibilidade de gerar de emprego e renda.

A agricultura urbana tem o potencial de agregar uma série de benefícios para melhoria do espaço urbano para efetivamente superar a condição de potencial e tornar-se realidade, porém é preciso que a agricultura urbana entre na pauta das políticas de gestão e planejamento urbano. Conforme apresentado, principalmente a partir da década de 1990, com a crescente preocupação relacionada ao meio ambiente e o desenvolvimento sustentável, houve a convergência de iniciativas regionais e globais de pesquisas e políticas voltadas para a AUP.

Atualmente, são diversos os exemplos de países, cidades e contextos em que a agricultura urbana é desenvolvida no mundo, com diferentes perspectivas e objetivos. É possível concluir que a agricultura urbana apresenta resultados positivos e tem como fator de convergência a participação dos governos mediante políticas públicas de planejamento e gestão territorial, concessão de crédito e assistência técnica, além da facilitação de acesso aos mercados. Outro ponto importante é o envolvimento da sociedade civil, por meio de associações, cooperativas, ONGs, e grupos organizados. Este é o caminho que deve direcionar projetos de política pública que objetivem a promoção e desenvolvimento da agricultura urbana como caminho para criar cidades mais verdes. 


\section{REFERÊNCIAS}

BARROS, R. C. Sustentabilidade na Agricultura e Geografia Agrária: o contexto da agricultura orgânica no Rio de Janeiro. In: Espaço Aberto. PPGG - UFRJ. v. 1, n. 1, p. 63-87, 2011. Disponível em:

<https://revistas.ufrj.br/index.php/EspacoAberto/article/view/2034 >. Acesso em: 20 Jan.2018.

BOURQUE, M. CAÑIZARES, K. Agricultura urbana em Havana: produção de alimentos na comunidade, pela comunidade e para a comunidade. In: Revista de Agricultura Urbana.v. 1, n. 1, p. 27-29, 2001. Disponível em:

<http://www.ruaf.org/sites/default/files/01compleet_0_1.pdf> . Acesso em: 02 Jan.2018.

BRANCO, M. C.; ALCÂNTARA, F. A. de. Hortas urbanas e periurbanas: o que nos diz a literatura brasileira? In: Horticultura Brasileira. v. 29, n. 3, p. 421-428, 2011.

Disponível em: <http://www.scielo.br/pdf/hb/v29n3/v29n3a28.pdf>. Acesso em: 20 Jul. 2018.

COMASSETO, B. H. et al. Nostalgia, anticonsumo simbólico e bem-estar: a agricultura urbana. RAE-Revista de Administração de Empresas. v. 53, n. 4, p. 364-375, 2013. Disponível em: < http://www.scielo.br/pdf/rae/v53n4/v53n4a04.pdf >. Acesso em: 20 Jul. 2018.

CRUZ, M. C.; MEDINA, R. S. Agricultura y ciudad: Una clave para la sustentabilidad. Havana, Cuba: Editorial Linotipia Bolfvar, 2001. Disponível em: < https://idl-bnc-idrc.dspacedirect.org/bitstream/handle/10625/26500/IDL26500.pdf? sequence $=1>$. Acesso em: 02 Jan.2018.

DISTRITO FEDERAL. Lei no 4.772, de 24 de fevereiro de 2012. Dispõe sobre diretrizes para as políticas de apoio à agricultura urbana e periurbana no Distrito Federal. Brasília: DODF, 2012.

ESPIRITO SANTO. Lei no 9.923, de 14 de novembro de 2012. Institui a Política Estadual de Assistência Técnica e Extensão Rural para a Agricultura Familiar e Reforma Agrária do Estado do Espirito Santo - PEATER/ES e o Programa Estadual de Assistência Técnica e Extensão Rural para a Agricultura Familiar e Reforma Agrária do Estado do Espírito Santo - PROATERES. Vitória: DOE, 2012.

FAO - Organização das Nações Unidas para Alimentação e Agricultura. Cuestiones de la agricultura urbana. Revista, 1999. Disponível em: <http://www.fao.org/ag/esp/revista/9901sp2.htm>. Acesso em 26 fev. 2018.

Criar cidades mais verdes. 2012. Disponível em:

<http://www.fao.org/ag/agp/greenercities/pt/hup/index.html>. Acesso em 14 jun. 2018. Ciudades más verdes em América Latina y el Caribe. Un informe de la FAO sobre la Agricultura Urbana y Periurbana en la región. Roma: FAO, 2014. 
Disponível em: <http://www.fao.org/ag/agp/greenercities/pdf/GGCLAC/Ciudades-masverdes-America-Latina-Caribe.pdf $>$. Acesso em 14 jun. 2018

Estructura y financiación. [S. 1.]. Disponível em:

http://www.fao.org/about/who-we-are/es/. Acesso em 14 jun. 2018

GOIÁS. Lei n⿳ 16.476, de 10 de fevereiro de 2009. Dispõe sobre a Política Estadual de Apoio à Agricultura Urbana e dá outras providências. Goiânia: DOE, 2009

HENRIQUES, J. C. Agricultura Urbana y Resiliencia en Lisboa: El papel del gobierno municipal. In: Revista de Agricultura Urbana. n. 22, p. 49-50, 2009. Disponível em: <https://www.ruaf.org/sites/default/files/RAU22.pdf>. Acesso em: 16 Jul.2018.

HESPANHOL, R. M. A agricultura urbana em Natal (RN): da produção convencional à orgânica. In: Revista franco-brasileira de geografia. n. 24, 2015. Disponível em: <https://journals.openedition.org/confins/10309> . Acesso em 20 Jul. 2018.

IDRC - INTERNATIONAL DEVELOPMENT RESEARCH CENTRE. About IDRC: The International Development Research Centre (IDRC) funds research in developing countries to promote growth, reduce poverty, and drive large-scale positive change. [S. 1.]. Disponível em: https://www.idrc.ca/en/about-idrc. Acesso em: 13 out. 2018.

LEVIDOW, L. et al. Agricultura Urbana e Involucramiento de la Comunidad en Manchester. In: Revista de Agricultura Urbana. v. 1, n. 24, p. 43-45, 2011. Disponível em: <https://www.ruaf.org/sites/default/files/Rau24.pdf>. Acesso em: 16 Jul.2018.

MACHADO, A. T.; MACHADO, C. T. de T. Agricultura urbana. Planaltina: Embrapa Cerrados, 2002.

MATO GROSSO. Lei no 314, de 12 de julho de 2016. Dispõe sobre a Política Estadual de Apoio à Agricultura Urbana e dá outras providências. Cuiabá: DOE, 2016.

MINAS GERAIS. Lei $\mathbf{n}^{0} \mathbf{1 5 . 9 7 3}$, de 12 de janeiro de 2006. Dispõe sobre a Política Estadual de Apoio à Agricultura Urbana e dá outras providências. Belo Horizonte: DOE, 2014.

MOLDAKOV, Oleg. Los agricultores urbanos de San Petersburgo. In: Revista de Agricultura Urbana.v. 1, n. 1, p. 24-26, 2001. Disponível em: <https://www.ruaf.org/sites/default/files/01compleet_0_1.pdf >. Acesso em: 16 Jul.2018.

MONTEIRO, A. V. V. M. AGRICULTURA URBANA E PERI-URBANA: questões e perspectivas. In: Informações Econômicas, São Paulo, v. 32, n. 6, p. 39-44, 2002. Disponível em: <http://www.iea.sp.gov.br/OUT/verTexto.php?codTexto=52>. Acesso em 27 fev. 2018.

MOREIRA, Crispim. Trajetórias contemporâneas da agricultura urbana. In: HISSA, C. E. V. (Org.). Saberes ambientais: desafios para o conhecimento disciplinar. Belo Horizonte: Ed. UFMG, 2008. p. 243-281. 
MOUGEOT, Luc J.A. Agricultura urbana: concepto y definción. Revista Agricultura Urbana. v.1, n.1, 2001, p.5-7. Disponível em 〈www.ruaf.org〉. Acesso em 26 fev. 2018.

International Support to Research and Policy on Urban Agriculture (19962010): achievements and challenges. Revista Agricultura Urbana - RUAF 10 years. n.25, 2011, p.12-17. Disponível em <www.ruaf.org>. Acesso em 26 fev. 2018.

MOURA, J. A.; FERREIRA, W. R.; LARA, L. de B. L. S. Agricultura urbana e periurbana. Mercator-Revista de Geografia da UFC, v. 12, n. 27, 2013. Disponível em: <http://www.redalyc.org/html/2736/273628670005/>. Acesso em 26 fev. 2018.

MULLINIX, K.; FALLICK, A.; HENDERSON, D. Más Allá de la Seguridad Alimentaria: La agricultura urbana como una forma de resiliencia en Vancouver, Canadá. In: Revista de Agricultura Urbana. n. 22, p. 41-42, 2009. Disponível em: $<$ https://www.ruaf.org/sites/default/files/RAU22.pdf >. Acesso em: 16 Jul.2018.

RIBEIRO, S. M.; et al. AGRICULTURA URBANA AGROECOLÓGICA: estratégia de promoção da saúde e segurança alimentar e nutricional. Revista Brasileira em Promoção da Saúde, v. 25, n. 3, p. 381-388, 2012. Disponível em: <https://periodicos.unifor.br/RBPS/article/view/2269> Acesso em: 9 fev. 2019.

RIBEIRO, S. M.; BÓGUS, C. M.; WATANABE, H. A. W.. Agricultura urbana agroecológica na perspectiva da promoção da saúde. Saúde e Sociedade, v. 24, p. 730743, 2015. Disponível em: <

http://www.periodicos.usp.br/sausoc/article/view/104846/103635Acesso em: 9 fev. 2019.

RIO DE JANEIRO. Lei no 3052, de 127 de junho de 2017. Institui a Política Estadual de Apoio à Agricultura Urbana na Região Metropolitana do Estado do Rio de Janeiro e estabelece seus mecanismos e dá outras providências. Rio de Janeiro: DOE, 2017.

RIO GRANDE DO SUL. Lei no 116, de 19 de junho de 2018. Dispõe sobre a Política Estadual de Apoio à Agricultura Urbana no Estado do Rio Grande do Sul. Porto Alegre: DOE, 2018.

ROYCROFT-BOSWELL, E. Perspectivas Orgánicas en Cuba. In: Revista de Agricultura Urbana.v. 1, n. 6, p. 21-21, 2002. Disponível em:

<http://www.ruaf.org/sites/default/files/06compleet_1.pdf >. Acesso em: 04 Jun.2018.

RUAF FOUNDATION. About RUAF. [S. 1.]. Disponível em:

https://www.idrc.ca/en/about-idrchttps://www.ruaf.org/about-ruaf. Acesso em: 13 out. 2018.

SANTA CATARINA. Lei $\mathbf{n}^{\mathbf{0}} \mathbf{1 7 . 5 5 3}$, de 19 de junho de 2018. Institui a Política Estadual de Apoio à Agricultura Urbana e estabelece outras providências. Florianópolis: DOE, 2018.

SANTANDREU, A.; LOVO, I. C. Panorama da agricultura urbana e periurbana no Brasil e diretrizes políticas para sua promoção: identificação e caracterização de iniciativas de AUP em regiões metropolitanas brasileiras. Documento Referencial 
Geral - Versão final. Belo Horizonte, 2007. Disponível em:

<http://www.agriculturaurbana.org.br/textos/panorama_AUP.pdf >. Acesso em: 17 Jun.2018.

SÃO PAULO. Lei no 16.684, de 19 de março de 2018. Institui a Política Estadual de Agroecologia e Produção Orgânica - PEAPO, e dá outras providências. São Paulo: DOE, 2018.

SIVIERO, A. et al. Plantas medicinais em quintais urbanos de Rio Branco, Acre. Rev. Bras. Pl. Med., Botucatu, v.14, n.4, p.598-610, 2012. Disponível em: <http://www.scielo.br/pdf/rbpm/v14n4/05.pdf>. Acesso em: 20 Jul.2018.

SPERANDIO, A. M. G. et al. Reverberações sociais e territoriais decorrentes de horta comunitária na perspectiva do planejamento urbano saudável. ARQUISUR Revista, v. 6, n. $10, \quad$ p. 72-83, $2016 . \quad$ Disponível em: $<$ https://bibliotecavirtual.unl.edu.ar/publicaciones/index.php/ARQUISUR/article/view/6 188/9321>. Acesso em: 20 Jul.2018. 